\title{
Efficiency of Mandibular Advancement Device and Bilevel Positive Airway Pressure Treatment for Severe Obstructive Sleep Apnea
}

\author{
${ }^{1}$ Filiz Keyf, ${ }^{2}$ Selma Firat, ${ }^{3}$ Bulent Ciftci
}

\begin{abstract}
Recently, attention to oral appliance therapy, as mandibular advancement device (MAD), has increased. Mandibular advancement device is a popular alternative treatment, particularly for mild to moderate obstructive sleep apnea (OSA). Oral appliances for treating severe OSA are recommended for patients who failed to comply with continuous positive airway pressure treatment. This clinical report presents the treatment outcome of oral appliance therapy and bilevel device in a 70-year-old man with severe OSA and also having respiratory disturbance index (RDI) of 62.7. Polysomnographic (PSG) evaluation was performed before and about 1 week after continuous use of the MAD and then with bilevel device. The results were compared, and RDI decreased 27.5 per hour with the custom MAD, whereas RDI decreased 3.1 per hour with bilevel device. Improved PSG parameters showed that bilevel device was efficient in treatment.
\end{abstract}

Keywords: Bilevel device, Mandibular advancement device, Obstructive sleep apnea.

How to cite this article: Keyf F, Firat S, Ciftci B. Efficiency of Mandibular Advancement Device and Bilevel Positive Airway Pressure Treatment for Severe Obstructive Sleep Apnea. Int J Experiment Dent Sci 2017;6(1):35-38.

Source of support: Nil

Conflict of interest: None

\section{INTRODUCTION}

Obstructive sleep apnea (OSA) is a disorder characterized with loud snoring, fragmented sleep, recurrent airway obstruction during sleep, and drowsiness in daytime that adversely affects quality of life. ${ }^{1}$ The upper airway obstruction can occur during sleep, as a result of various conditions. Anatomic variations of airline-related sections

\footnotetext{
${ }^{1,3}$ Professor, ${ }^{2}$ Associate Professor

${ }^{1}$ Department of Prosthodontics, Faculty of Dentistry, Hacettepe University, Ankara, Sihhiye, Turkey

${ }^{2}$ Department of Sleep Disorders Center, Ataturk Chest Diseases and Thoracic Surgery Training and Research Hospital Ankara, Sanatoryum, Turkey

${ }^{3}$ Department of Chest Diseases, Faculty of Medicine, Bozok University, Yozgat, Turkey

Corresponding Author: Filiz Keyf, Professor, Department of Prosthodontics, Faculty of Dentistry, Hacettepe University Ankara, Sihhiye, Turkey, Phone: +903123054075 , e-mail: fkeyf@hacettepe.edu.tr
}

in development, being overweight, and prone position can be some of the causes of OSA. These patients may experience cardiac arrhythmias, angina, myocardial infarction, mental problems, and also OSA can lead to more serious consequences, such as traffic accidents. Snoring or subjective data are not sufficient for diagnosis. Definitive diagnosis can only be done with polysomnography (PSG), which is performed by sleeping in a sleep laboratory. ${ }^{1-4}$

The treatment of OSA extends from surgical treatment to conservative treatment. Obstructive sleep apnea therapy can be summarized in four main categories: Behavior modification, the use of continuous positive airway pressure (CPAP) device, the use of oral appliances, and surgical approaches. ${ }^{1,3,5}$ With mandibular advancement device (MAD) treatment, the goal is to prevent the narrowing of the airway during sleep by positioning the mandible in a forward place. ${ }^{6}$ When compared with other methods of treatment of OSA, oral appliances have advantages, such as being able to be better tolerated by patients, cheaper, simple, noninvasive, reversible, and reduced clinic hours. ${ }^{3}$ Oral appliances are an alternative to CPAP for the treatment of OSA. Especially, MAD is an alternative treatment in patients who cannot tolerate CPAP or bilevel device.

In this clinical report, the outcome of treatment MAD and bilevel device for a patient who is intolerant to bilevel PAP treatment with severe OSA is presented. The therapeutic effects were analyzed.

\section{CASE REPORT}

A 70-year-old man was admitted to the Department of Prosthodontics, Faculty of Dentistry, Hacettepe University, Ankara, Turkey, with a history and diagnosis of loud snoring and OSA. Previously, he was examined in the Sleep Disorders Center of Atatürk Chest Diseases and Chest Surgery Education and Research Hospital and then referred to our clinic. The patient underwent a full-night PSG, using the Compumedics Voyager Digital Imaging 44-Channel E-Series System (Compumedics ${ }^{\circledR}$, Melbourne, Victoria, Australia). Sleep stages as well as respiratory parameters were scored according to the standard criteria of the American Academy of Sleep Medicine. The patient was diagnosed with severe OSA 
with rhythmic limb movement in sleep, and having respiratory disturbance index (RDI) of 62.7.

An extraoral and intraoral examination was made. Intermaxillary relationship was evaluated using diagnostic casts and panoramic radiograph. There was no problem with the teeth and the periodontal tissues; class I occlusion was observed. Palpation and auscultation were applied for temporamandibular joint evaluation. He had no periodontal and temporomandibular diseases. Muscle palpation and motion range of the jaw, such as maximum opening (45 $\mathrm{mm})$, lateral and protrusive movements $(>7 \mathrm{~mm})$ were also evaluated. Neck size, obesity, oropharyngeal tissues, size of the tongue, length of the soft palate, and size of the uvula, tonsils, and crowding of oropharyngeal area were other parameters of examination. All of the aforementioned parameters were normal. He had no reversible morphological upper airway abnormalities (enlarged tonsils) as assessed by ear, nose, and throat specialists. There was no nasal breathing problems. He had no medication that could influence respiration or sleep. His body mass index was $29.2 \mathrm{~kg} / \mathrm{m}^{2}$. Sleep study showed RDI as 62.8 and oxygen desaturation index as 65.0. The patient could not tolerate CPAP because of the feeling of difficulty breathing out. So he was titrated by using bilevel device. Bilevel positive airway pressure (PAP) device was found efficient with the pressure of $13 \mathrm{~cm} \mathrm{H}_{2} \mathrm{O}$ for inspiratory PAP and $9 \mathrm{~cm} \mathrm{H}_{2} \mathrm{O}$ for expiratory PAP. Bilevel PAP treatment was recommended but the patient did not accept. It was decided for MAD treatment.

Maxillary and mandibular impressions were obtained with irreversible hydrocolloid impression material (Kromopan; Lascod, Firenze, Italy), and casts were obtained with the use of a dental stone type III (Moldano; Bayer Co., Leverkusen, Germany). The interocclusal records were obtained with the patients protruded $75 \%$ of their maximum protrusive movement.

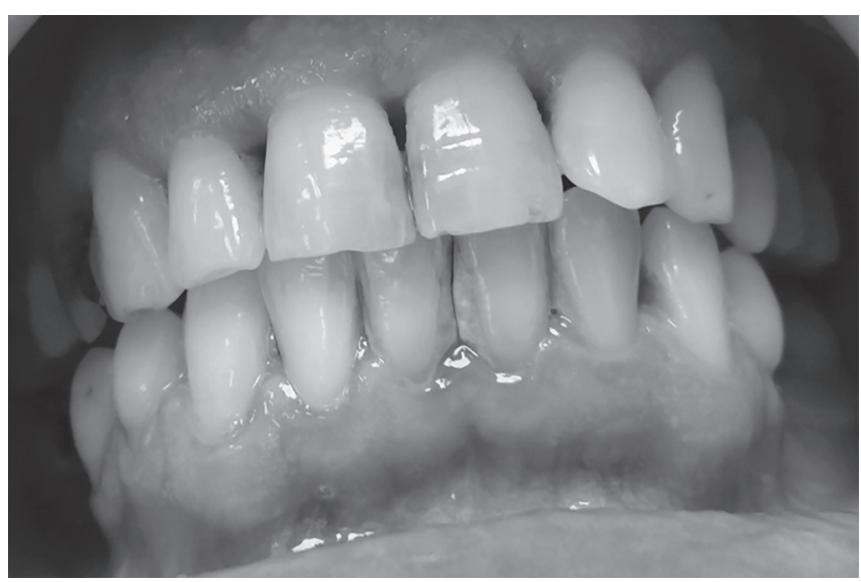

Fig. 1: The patient's occlusion
The method described by Taylor ${ }^{2}$ was used. Vertical dimension was increased by $3 \mathrm{~mm}$. The acrylic resin bases were prepared with heat-polymerized acrylic resin (Meliodent, Heraeus Kulzer, Germany). When polymerization of the acrylic was complete, finishing and polishing were performed. The appliance was evaluated in the patient's mouth for any possible discomfort (Figs 1 and 2). The patient was able to breathe comfortably through the nasal airway and the breathing hole on the appliance. Instructions for use and care were provided at insertion. The patient was advised to wear the appliance for at least 6 hours during night, and was recalled 1 week later. At the first weekly review, the patients reported that his sleep at night had improved and daytime somnolence had diminished. The patient underwent PSG follow-up recordings after 1 week and the RDI was 27.5. For severe RDI, bilevel device was administered to the patient. Changes were evaluated during bilevel device treatment and RDI was 3.1 (Table 1).

\section{RESULTS}

A comparison of baseline and 1st week follow-up PSG with MAD and bilevel device data is shown in Table 1.

The patient with MAD reported a favorable sleeping pattern without any discomfort on evaluation appointments after 1 week. He reported that snoring, wake gasping, and choking were reduced drastically. The RDI significantly decreased from 62.7 to 27.5 with the appliance. Concerning sleep architecture, showing the quality of sleep, stages of N3 and rapid eye movement (REM) sleep showed an increase significantly. N3 sleep time increased from 42 minutes $(8.7 \%)$ to 129 minutes (28.4\%), RDI REM decreased from 78.0 to 26.4, RDI non-REM decreased from 60.9 to 27.6, and total RDI decreased from 62.7 to 27.5. The average oxygen saturation did not improve as expected initially. Oxygen desaturation index decreased from 65.0 to 29.0 .

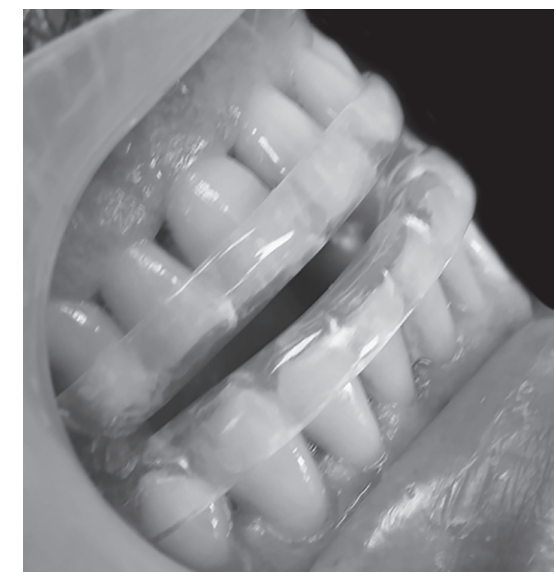

Fig. 2: With MAD 
Table 1: Change in RDI and the other parameters with MAD and bilevel device use for severe OSA

\begin{tabular}{|c|c|c|c|}
\hline & $\begin{array}{l}\text { Diagnostic sleep test } \\
\text { June 11, } 2015\end{array}$ & $\begin{array}{l}\text { With MAD } \\
\text { June } 19,2015\end{array}$ & $\begin{array}{l}\text { With bilevel PAP device } \\
\text { June 22, } 2015\end{array}$ \\
\hline Total recording time (min) & 532.0 & 479.0 & 447.0 \\
\hline Total sleep time (min) & 485.5 & 454.0 & 351.0 \\
\hline Sleep latency $(\min )$ & 1.5 & 13.0 & 13.0 \\
\hline REM latency (min) & 106.5 & 179.0 & 55.0 \\
\hline Sleep efficiency (\%) & 91.3 & 94.8 & 78.5 \\
\hline Total REM sleep time (min) & $\begin{array}{l}50.0 \min \\
10.3 \%\end{array}$ & $\begin{array}{l}45.5 \min \\
10.0 \%\end{array}$ & $\begin{array}{l}128.5 \min \\
36.6 \%\end{array}$ \\
\hline Total stage N1 sleep time & $\begin{array}{l}74.5 \mathrm{~min} \\
15.3 \%\end{array}$ & $\begin{array}{l}21.0 \mathrm{~min} \\
4.6 \%\end{array}$ & $\begin{array}{l}9.5 \min \\
2.7 \%\end{array}$ \\
\hline Total stage N2 sleep time & $\begin{array}{l}319.0 \min \\
65.7 \%\end{array}$ & $\begin{array}{l}258.5 \min \\
56.9 \%\end{array}$ & $\begin{array}{l}114.0 \mathrm{~min} \\
32.5 \%\end{array}$ \\
\hline Total stage N3 sleep time & $\begin{array}{l}42.0 \min \\
8.7 \%\end{array}$ & $\begin{array}{l}129.0 \min \\
28.4 \%\end{array}$ & $\begin{array}{l}99.0 \min \\
28.2 \%\end{array}$ \\
\hline RDI REM & 78.0 & 26.4 & 1.9 \\
\hline RDI non-REM & 60.9 & 27.6 & 5.3 \\
\hline Total RDI & 62.7 (severe) & 27.5 (moderate) & 3.1 (mild) \\
\hline Total number of obstructive apneas & 75 & 21 & 3 \\
\hline Total number of mixed apneas & 28 & 1 & 0 \\
\hline Total number of central apneas & 20 & 0 & 0 \\
\hline Total number of hypopneas & 384 & 187 & 15 \\
\hline Maximum apnea duration (sec) & 46.5 & 18.5 & 18.1 \\
\hline Total respiratory events & 507 & 209 & 18 \\
\hline Mean $\mathrm{SpO}_{2}(\%)$ & 94 & 93 & 91 \\
\hline Lowest $\mathrm{SpO}_{2}(\%)$ & 81 & 88 & 86 \\
\hline RDI supine & 0 & 2.9 & 4.4 \\
\hline RDI right side & - & 189.2 & 2.7 \\
\hline RDI left side & 52.6 & 261.9 & 2.8 \\
\hline RDI prone & 86.4 & - & 0 \\
\hline Oxygen desaturation index & 65.0 & 29.0 & 3.6 \\
\hline Mean heart rate & 72 & 69 & 68 \\
\hline
\end{tabular}

$\mathrm{SpO}_{2}$ : Oxygen saturation by pulse oximeter; RDI: Apnea + hypopnea + RERA (Respiratory Effort Related Arousal)/hour

With bilevel device, total RDI significantly decreased from 62.7 to 3.1, RDI REM decreased from 78.0 to 1.9 , and RDI non-REM decreased from 60.9 to 5.3. The average oxygen saturation did not improve as expected initially. Oxygen desaturation index decreased from 65.0 to 3.6 .

\section{DISCUSSION}

Intraoral appliances are generally indicated for mild to moderate OSA as an alternative to CPAP or craniofacial surgery. ${ }^{4,7-11}$ Although CPAP is proved to be more efficient in treatment, it is not tolerated well by patients; therefore, intraoral appliances are frequently preferred ${ }^{3,5,12-16}$ as in this patient.

Treatment success is commonly defined by a reduction in $\mathrm{RDI}$ to $<5$ or $<10$ in addition to a $<50 \%$ reduction in baseline RDI. ${ }^{5-8,17,18}$ The patient's RDI decreased from 62.7 to 27.5 with the oral appliance in use. The PSG results confirmed that the treatment was successful in accordance with the literature. The patient indicated that his quality of life had improved and that he was comfortable with the device. These findings show that patient benefited from the oral device. But it was not enough.

For most patients with OSA, CPAP is an effective therapy. However, for a subset of individuals, CPAP is either not effective or is poorly tolerated. Bilevel PAP is potentially capable of treating OSA at a lower mean pressure than CPAP and can help augment ventilation via pressure support. 19,20

Bilevel PAP systems may be particularly helpful for patients with coexisting lung disease and those with excessive levels of carbon dioxide. These devices have a sensing feature that helps determine and vary the appropriate pressure depending on whether a person is breathing in or out. Greater pressure is needed on inhalation and less on exhalation. Because of this, bilevel device was preferred.

Both active treatments resulted in decreases in apnea and hypopnea index; bilevel device showed a greater effect.

\section{CONCLUSION}

This clinical report compared efficacy of MAD therapy and bilevel device therapy. Although oral appliances have 
been shown to be less effective than nasal CPAP therapy, these appliances should still be considered when patients are intolerant to CPAP or bilevel device treatment as our patient or had an unsuccessful surgery.

\section{ACKNOWLEDGMENT}

Authors would like to thank Hacettepe University and Sleep Disorders Center, Ataturk Chest Diseases, and Thoracic Surgery Training and Research Hospital.

\section{REFERENCES}

1. Barewal RM, Hagen CC. Management of snoring and obstructive sleep apnea with mandibular repositioning appliances: a prosthodontic approach. Dent Clin North Am 2014 Jan;58(1):159-180.

2. Taylor, TD. Clinical maxillofacial prosthetics. Berlin: Quintessence Publishing Co., Inc.; 2000.

3. Kim YK, Kim JW, Yoon IY, Rhee CS, Lee CH, Yun PY. Influencing factors on the effect of mandibular advancement device in obstructive sleep apnea patients: analysis on cephalometric and polysomnographic parameters. Sleep Breath 2014 May;18(2):305-311.

4. Marklund M, Verbraecken J, Randerath W. Non-CPAP therapies in obstructive sleep apnea: mandibular advancement device therapy. Eur Respir J 2012 May;39(5):1241-1247.

5. Remmers J, Charkhandeh S, Grosse J, Topor Z, Brant R, Santosham P, Bruehlmann S. Remotely controlled mandibular protrusion during sleep predicts therapeutic success with oral appliances in patients with obstructive sleep apnea. Sleep 2013 Oct; 36(10):1517-1525, 1525A.

6. Chan AS, Sutherland K, Schwab RJ, Zeng B, Petocz P, Lee RW, Darendeliler MA, Cistulli PA. The effect of mandibular advancement on upper airway structure in obstructive sleep apnea. Thorax 2010 Aug;65(8):726-732.

7. Fukuda T, Tsuiki S, Kobayashi M, Nakayama H, Inoue Y. Selection of response criteria affects the success rate of oral appliance treatment for obstructive sleep apnea. Sleep Med 2014 Mar;15(3):367-370.

8. Ferguson KA, Cartwright R, Rogers R, Schmidt-Nowara W. Oral appliances for snoring and obstructive sleep apnea: a review. Sleep 2006 Feb;29(2):244-262.
9. Kushida CA, Morgenthaler TI, Littner MR, Alessi CA, Bailey D, Coleman J Jr, Friedman L, Hirshkowiz M, Kapen S, Kramer M, et al. Practice parameters for the treatment of snoring and obstructive sleep apnea with oral appliances: an update for 2005. Sleep 2006 Feb; 29(2):240-243.

10. Keyf F, Ciftci B, Firat Guven S. Management of obstructive sleep apnea in an edentulous lower jaw patient with a mandibular advancement device. Case Rep Dent 2014 Jan; 2014: 436904.

11. Keyf F, Akta G, Keyf IA. Efficacy of mandibular advancement devices in two patients with moderate obstructive sleep apnea: case reports. CDJ 2015 Feb;18(1):79-85.

12. Dort LC, Hadjuk E, Remmers JE. Mandibular advancement and obstructive sleep apnea: a method for determining effective mandibular protrusion. Eur Respir J 2006 May;27(5): 1003-1009.

13. Ferguson KA, Ono T, Lowe AA, Keenan SP, Fleetham JA. A randomized crossover study of an oral appliance vs nasalcontinuous positive airway pressure in the treatment of mildmoderate obstructive sleep apnea. Chest 1996 May;109(5): 1269-1275.

14. Dort L, Brant R. A randomized, controlled, crossover study of a noncustomized tongue retaining device for sleep disordered breathing. Sleep Breath 2008 Nov;12(4):369-373.

15. White J, Cates C, Wright J. Continuous positive airways pressure for obstructive sleep apnea. Cochrane Database Syst Rev 2002; 2002(2): Cd001106.

16. Haviv Y, Bachar G, Aframian DJ, Almoznino G, Michaeli E, Benoliel R. A 2-year mean follow-up of oral appliance therapy for severe obstructive sleep apnea: a cohort study. Oral Dis 2015 Apr;21(3):386-392.

17. Lettieri CJ, Paolino N, Eliasson AH, Shah AA, Holley AB. Comparison of adjustable and fixed oral appliances for the treatment of obstructive sleep apnea. J Clin Sleep Med 2011 Oct;7(5):439-445.

18. Wagle S, Kalia P, Shahi H, Agarwal KK, Jain P. Sleep apnea and its management: a review. Int J Enhanc Res Med Dent Care 2014 May;1(3):29-34.

19. White DP, Shafazand S. Mandibular advancement device vs CPAP in the treatment of obstructive sleep apnea: are they equally effective in short term health outcomes? J Clin Sleep Med 2013 Sep; 9(9):971-972.

20. Mansukhani MP, Kolla BP, Olson EJ, Ramar K, Morgenthaler TI. Bilevel positive airway pressure for obstructive sleep apnea. Expert Rev Med Devices 2014 May;11(3):283-294. 